\title{
Soluble form of carbonic anhydrase IX (CA IX) in the serum and urine of renal carcinoma patients
}

\author{
J Závada*, I, Z Závadová', M Zat'ovičová ${ }^{2}$, L Hyršs| ${ }^{3}$ and I Kawaciuk ${ }^{3}$ \\ 'Institute of Molecular Genetics, Academy of Sciences of the Czech Republic, Flemingovo nám. 2, 16637 Prague, Czech Republic; ${ }^{2}$ Institute of Virology, \\ Slovak Academy of Sciences, Dúbravská cesta 9, 84245 Bratislava, Slovakia; ${ }^{3}$ Clinic of Urology, Charles University, 2nd School of Medicine, 15000 \\ Prague, Czech Republic
}

\begin{abstract}
Tumour-associated protein carbonic anhydrase IX (CA IX) has two major forms. One is a cell-associated, transmembrane protein seen on Western blots as a twin band of $54 / 58 \mathrm{kDa}$, expressed in gastric mucosa and in several types of cancer. The other is a soluble protein s-CA IX of 50/54 kDa, which is released into the culture medium or into the body fluids, most likely by proteolytic cleavage of the extracellular part from transmembrane and intracellular sequences. While TC media of CA IX-positive tumour cell lines or shortterm cultures of tumour explants contain a relatively high concentration of s-CA IX $\left(20-50 \mathrm{ng} \mathrm{ml}^{-1}\right)$, the level of this antigen in blood serum and urine of renal clear cell carcinoma patients is about $1000 \times$ lower. The concentration of CA IX in the blood and in urine varies within wide limits and there is no obvious correlation with tumour size. After nephrectomy, s-CA IX is cleared from the blood within a few days. Only an extremely low concentration of CA IX was detectable in the sera and in urine of control individuals. British Journal of Cancer (2003) 89, 1067-107I. doi:I0.1038/sj.bjc.660I264 www.bjcancer.com
\end{abstract} (c) 2003 Cancer Research UK

Keywords: carbonic anhydrase IX; tumour antigens; cancer diagnostics

Carbonic anhydrase IX (CA IX) protein (previously named as MN or MN/CA IX) is a cell membrane protein (Pastoreková et al, 1992; Závada et al, 1993), which is ectopically expressed in various human tumours, mostly carcinomas, for example, cervical, renal, colorectal, lung, mammary and others (Liao et al, 1994, 1997; Saarnio et al, 1998). It has been suggested that CA IX may serve as a biomarker in early stages of tumorigenesis; now it is turning out to be induced in certain tumours by hypoxia, which is connected with poor prognosis (Chia et al, 2001; Giatromanolaki et al, 2001; Koukorakis et al, 2001). In renal clear cell carcinoma (RCC), synthesis of CA IX is switched on by the loss of suppressor gene VHL (Ivanov et al, 1998). Until recently, the identification of CA IX in formaldehyde-fixed, paraffin-embedded tumour sections has been based on immunohistochemical analysis using MAb M75.

On the other hand, there were no reports on detecting CA IX in body fluids of cancer patients. For the assays of soluble antigens, which are usually present only in extremely low concentrations, two antibodies are needed, preferably monoclonal, directed to different epitopes. One of them serves for concentrating the antigen and the other for its detection and quantitation. However, all efforts to raise antibodies specific for epitopes different from the M75 epitope have failed. This represented the crucial problem, which we succeeded to solve.

Our approach was based on the following consideration: sequencing of Car9, the mouse homologue of human CA9 gene, revealed that the $\mathrm{N}$-terminal, proteoglycan-like (PG) domain of the protein shows almost no homology between man and mouse. The carbonic anhydrase (CA) domain is relatively conserved in evolution. Therefore, the mouse will recognise human PG as 'nonself and be able to respond to it immunologically, but it will not

*Correspondence: Dr J Závada; E-mail: zavada@img.cas.cz Received 7 February 2003; revised 9 June 2003; accepted I 6 July 2003 produce antibodies reacting with human CA domain. However, mice with the disrupted Car 9 gene (knockout) should be able to produce antibodies against different antigenic sites of the CA IX protein.

Indeed, Zat'ovičová et al (2003), taking advantage of Car9-Imice constructed by Ortová-Gut et al (2002), was able to produce a series of potent monoclonal antibodies (mAbs) specific for different antigenic sites, many of which are located in the CA domain (e.g. the V-10 antibody used in this report). The epitope of our original M75 antibody is located in the PG domain of CA IX and its amino-acid sequence is PGEEDLP (Závada et al, 2000).

Using newly obtained mAbs, we were able to develop tests for the s-CA IX antigen. To start with, we decided to use tumour cell cultures as an easy model system. The first set of questions we started to ask were: (1) Do the tumour cells containing cellassociated CA IX also shed this antigen into the medium during cultivation? (2) Is the soluble form of CA IX different from cellassociated molecules? (3) What is the concentration of CA IX in the media? (4) Do short-term cultures of human tumours also shed s-CA IX, and if they do, how much of it? (5) Can soluble CA IX be detected in the serum and urine of the patients? (6) How fast is the clearance of CA IX from the blood and from urine after surgical removal of the tumour? (7) What is the dependence of CA IX concentration in body fluids on the tumour size? (8) Do the blood and urine of healthy individiuals also contain CA IX?

In the present experiments, we chose the patients with RCC because these tumours usually express CA IX to a high level and in a high proportion of the patients.

\section{MATERIALS AND METHODS}

\section{Patients and controls}

The study included 50 patients ( 28 men and 22 women, mean age 63. 2 years, range $36-79$ ) with newly diagnosed RCC. All patients 
routinely underwent ultrasound and CT before surgery to obtain information for the standard staging protocol. Serum and urine from these patients were obtained before surgery and 5 days after it. In some patients, a sample of tumour tissue after nephrectomy was used for short-term RCC cultures. In all patients the diagnosis was confirmed histologically. In total, 18 patients served as controls; these had been admitted to the hospital for other urological conditions than RCC (infections, urinary stones, other urological tumours, etc.). Other control sera were obtained from healthy blood donors. The study had been approved by the Departmental Ethics Committee.

\section{Cell and tumour cultures and media}

The cell line HT29 (DSMZ ACC299) derived from colorectal carcinoma and A498 (ATCC No. HTB-44) derived from RCC were grown in Dulbecco's modified Eagle's medium (DMEM) supplied with $10 \%$ foetal calf serum (FCS, Gibco). Short-term cultures of the tumours were fresh tumour excisions cut in $1 \mathrm{~mm}$ pieces, rinsed with phosphate-buffered saline (PBS, $\mathrm{pH}$ 7.2), suspended in DMEM with $10 \%$ FCS (about $50-100 \mathrm{mg}$ of fresh weight of tumour fragments in $5 \mathrm{ml}$ of the medium) and incubated in $5 \mathrm{~cm}$ Petri dishes at $37^{\circ} \mathrm{C}$ in a $5 \% \mathrm{CO}_{2}$ incubator. Cell lysis buffer constitutes PBS with 1\% Igepal CA-630 (Sigma), 0.25\% deoxycholate and proteinase inhibitors (1 mM phenylmethylsulphonyl fluoride and 200 trypsin-inhibiting units of Trasylol per $\mathrm{ml}$ ).

\section{Immunological reagents and methods}

Monoclonal antibodies M75 specific for the PG region of CA IX has been produced by Pastoreková et al (1992) and V-10 specific for CA domain, by Zat'ovičová et al (2003). The isotype of $\mathrm{mAb}$ M75 is IgG $2 b$ and that of V-10 is IgG $2 a$. The IgG was purified from hybridoma TC fluid by affinity chromatography as previously (Závada et al, 2000). For the concentration of immune complexes formed by the mAbs with CA IX, antigen from TC media or cell extracts Protein A-Sepharose (Sigma) was used: the mAb-CA IX complexes from human sera or urine were adsorbed to anti-mouse IgG-Agarose (Sigma). The immunoperoxidase conjugate M75-Px was prepared using the peroxidase labelling kit (Roche Diagnostics, GmBH, Mannheim, Germany).

Immunoprecipitation of s-CA IX from human sera and urine was carried out as follows: to $0.75 \mathrm{ml}$ of serum or $10 \mathrm{ml}$ of urine (both clarified by centrifugation) were added $2 \mu \mathrm{g}$ of M75 $\mathrm{IgG}$ and allowed to react for $60 \mathrm{~min}$ at room temperature. Following this, each sample was supplied with $50 \mu \mathrm{l}$ of $50 \%$ pre-washed antimouse IgG agarose beads and the suspension was agitated in a rotator for $4 \mathrm{~h}$ or overnight at $+4^{\circ} \mathrm{C}$. Then the beads with bound mouse IgG and immune complexes were centrifuged (1200 r.p.m. $2 \mathrm{~min}^{-1}$ ), the pellet was resuspended in $1 \mathrm{ml}$ PBS with $0.05 \%$ Tween 20 (PBS-T, Sigma) centrifuged as above and the beads were heated at $100^{\circ} \mathrm{C}$ for $5 \mathrm{~min}$ in $60 \mu \mathrm{l}$ of Laemmli sample buffer supplied with $1.5-2 \%$ of FCS (for reasons explained in the last paragraph of Results).

ELISA The 'sandwich' was composed of these layers: (1) Microtitre plates or strips were coated with mAb V-10 IgG, $5 \mu \mathrm{g} \mathrm{ml}^{-1}$ in $50 \mathrm{~mm}$ carbonate buffer $\mathrm{pH} 9.6$ which was adsorbed $3 \mathrm{~h}$ at room temperature, (2) test antigen dilutions in PBS with $1 \%$ FCS were adsorbed overnight at $+4^{\circ} \mathrm{C}$, (3) M75-Px conjugate $1: 5000$ in PBS with 1\% FCS was allowed to bind for $2 \mathrm{~h}$ at room temperature, (4) orthophenylene diamine (OPD, Sigma), $1 \mathrm{mg} \mathrm{ml}^{-1}$ in $100 \mathrm{~mm}$ phosphate/citrate buffer $\mathrm{pH} 5.0+1 \mu \mathrm{l} \mathrm{ml} \mathrm{l}^{-1}$ of $30 \% \mathrm{H}_{2} \mathrm{O}_{2}$ (Sigma), was allowed to react $30 \mathrm{~min}$ in the dark at room temperature. After steps $1-3$, the plates were washed $\times 4$ with PBS-T. The reaction was terminated by adding two drops of $2 \mathrm{~N}$ $\mathrm{H}_{2} \mathrm{SO}_{4}$ per well. We have used the MaxiSorp strips or plates (NUNC, Denmark).
Western blot analysis Sodium dodecyl sulphate - polyacrylamide gel electrophoresis and Western blotting were performed as described before (Závada et al, 2000). Carbonic anhydrase IX antigen on the blots was visualised by M75-Px conjugate, followed by enhanced chemiluminescence (ECL) and exposure to X-ray film Medix XG (FOMA, Czech Republic), with maximum sensitivity to yellow-green light.

\section{RESULTS}

\section{Cell-associated and soluble CA IX in cell cultures}

Various human tumour cell lines, when grown to a high density, produce CA IX seen on Western blots as a 'twin' protein p54/58 (Pastoreková et al, 1992; Závada et al, 1993). The present results are consistent with these reports (Figure 1). The HT29 cell line derived from colorectal carcinoma shows 54 and $58 \mathrm{kDa}$ bands of CA IX on Western blots. Media from these cell cultures also contain CA IX, but the molecules of the soluble form are somewhat shorter, with two bands of 50 and $54 \mathrm{kDa}$. The total content of CA IX in the cell extract is about 10x higher than in the medium, as determined by ELISA (Figure 2). The A498 cells are poor producers of CA IX.

\section{CA IX in tumour extracts and in media of short-term cultures of RCC}

Western blots of the extracts from RCC tumours resemble blots of tumour cell cultures. They also contain two bands of 54 and $58 \mathrm{kDa}$ and the proportion of CA IX per total protein is somewhat lower than in HT29 cells (Figures 1 and 2). All the six RCC tumour extracts were strongly CA IX positive. Control kidneys and a nonRCC tumour, an angiolipoma, did not contain any CA IX.

Shedding of s-CA IX was examined in short-term cultures: the medium from a suspension culture of tumour fragments was harvested after 2 days and analysed by ELISA and Western blotting. Again, both the concentration and $M_{\mathrm{r}}$ of s-CA IX were comparable with the cultures of permanent tumour cell lines such as HT29.

\section{CA IX in the serum of RCC patients}

There were no problems with detection and quantitation of the CA IX protein in extracts from cells or tumours and in culture media. The concentration of CA IX was sufficient for direct analysis by Western blotting or by ELISA. Control cell extracts or media showed no false positivity or nonspecific bands.

However, it was necessary to concentrate the CA IX protein from the sera and urine of RCC patients before gel electrophoresis and Western blotting.

We tested 30 samples of sera from RCC patients, 14 sera of patients with tumours other than RCC, six sera of nontumour

\section{HT29}

Tumours + controls

Media

\section{$\begin{array}{lllllllllllllll}\mathrm{kDa} & \mathrm{M} & \mathrm{C} & \mathrm{M} & 29 & 31 & 27 & \mathrm{~K} 149 & 50 & 59 & \mathrm{~K} 2 & 38 & 38 & 50 & 59\end{array}$}

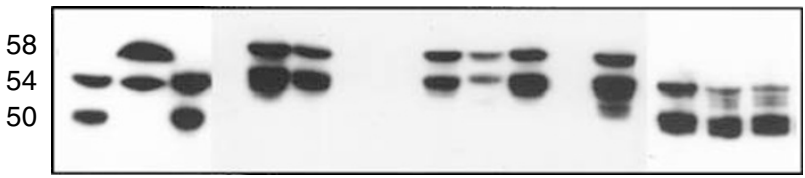

Figure I Western blot analysis of CA IX in culture media or in extracts from cells, tumours and control tissues. HT29: $M=$ medium, $C=$ cell extract. Numbers above the remaining lanes=codes for the patients; $\mathrm{KI}$, $\mathrm{K} 2=$ control kidneys; no. $27=$ angiolipoma; all other lanes=RCC. The lanes were loaded with $25 \mu \mathrm{l}$ of media or with $\mid 2.5 \mu \mathrm{l}$ of cell or tumour extracts adjusted to I $\mathrm{mg}$ of total protein per $\mathrm{ml}$. 
A

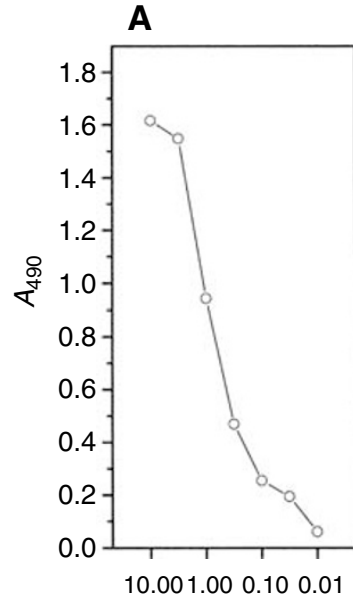

B

\section{C}

CA IX (ng ml-1)

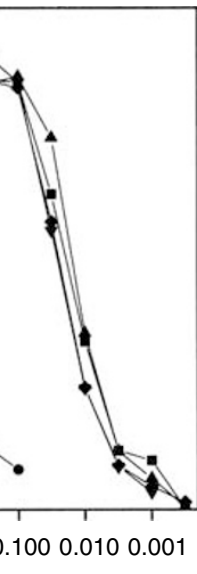

Dilution of media

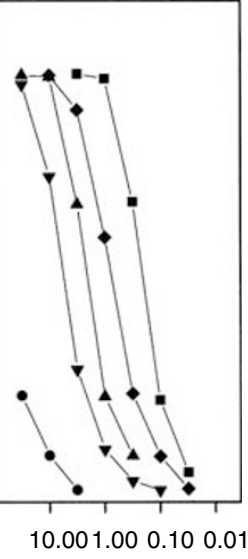

$\mu \mathrm{g} \mathrm{ml}^{-1}$ Total protein

Figure 2 ELISA test for CA IX antigen. The numbers of tumour materials correspond to the patients in Figure I. HT29 cells grew in a $5 \mathrm{~cm}$ Petri dish, supplied with $5 \mathrm{ml}$ of media, exchanged 2 days before harvest. The extract from the cell monolayer in this culture contained $5 \mathrm{mg}$ of total protein. Extracts from the tumours were prepared directly from the excisions, without previous cultivation in vitro. Media from the cultures of tumour fragments were harvested after 2 days. (A) Purified CA IX protein (described in Závada et al, 2000); (B) TC media; (C) extracts from cells and tumours; $O=$ purified $C A \mid X ; 0=A 498$ cells; $\mathbf{\square}=\mathrm{HT} 29$ cells; patients no. $\boldsymbol{\Delta}=38 ; \boldsymbol{\nabla}=50 ; \bullet=59$.

patients suffering from various urological diseases and 42 sera of healthy blood donors. Sera evaluated as positive were found mainly in the RCC group. Out of total 30 RCC sera, 12 scored as 'positive' (40\%). The RCC group included one sarcomatous RCC, which was CA IX positive. Among 14 non-RCC tumour patients, one was positive (papillary carcinoma).

An example of our tests is shown in Figure 3 (top panel). There does not seem to be a clear correlation between the tumour size and the concentration of CA IX in the serum. All sera evaluated as 'negative', including sera of healthy blood donors, did in fact show an extremely weak $50 \mathrm{kDa}$ band of s-CA IX, which became well visible only after prolonged exposure of the blots.

To obtain more support for the presumed origin of blood s-CA IX from the tumours, we tested several paired sera from RCC patients before and after nephrectomy (Figure 3, bottom panel). Indeed, in three cases the postoperation sera contained much less of s-CA IX than the corresponding preoperation sera. One exception was patient no. 68, showing a postoperation increase of the s-CA IX level - but this patient underwent only a palliative operation. Only a moderate decrease of s-CA IX was seen in patient no. 104; in his case sample A was taken only 1 day after nephrectomy, whereas in all other patients it was obtained 5 days after operation.

\section{CA IX in urine}

The RCC patients excrete s-CA IX protein in urine (Figure 4). For obvious reasons, we could afford concentrating the antigen from $10 \mathrm{ml}$ of urine (or from larger volumes if needed), and loading one lane on the gel with an aliquot corresponding to $8 \mathrm{ml}$. It is turning out that a relatively high percentage $(19 / 27=70 \%)$ of the patients excrete CA IX in urine. $M_{\mathrm{r}}$ of the protein is about the same as in blood. Some of the urine samples showed additional bands of intermediate size. In two strongly positive samples (nos. 50 and 54), there was an additional band of $62 \mathrm{kDa}$. Control specimens of urine from 25 healthy persons, two nontumour and three non-RCC tumour urology patients were all CA IX negative.

s-CA IX concentrated from human sera
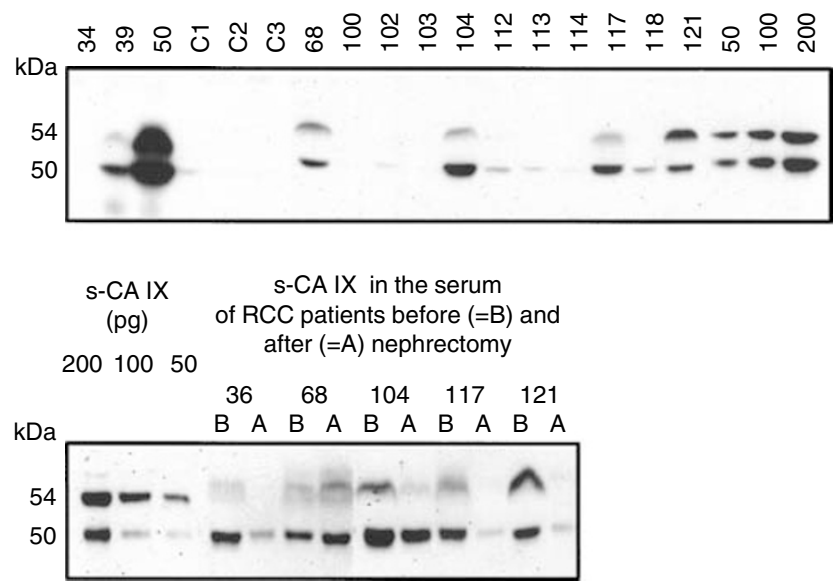

Figure 3 Carbonic anhydrase IX protein in the sera of RCC patients and of control individuals. Each lane was loaded with immunoprecipitate corresponding to original $0.6 \mathrm{ml}$ of the serum. Lane designation: $\mathrm{Cl}-$ $\mathrm{C} 3=$ healthy blood donors; $100=$ stones in the urether; non-RCC tumours: $39=$ papillary carcinoma from renal cells, I03=urothelial tumour of renal pelvis, $121=$ sarcomatoid renal carcinoma; all other samples $=$ RCC (the largest are no. $68=2350 \mathrm{~cm}^{3}$, no. $36=1466 \mathrm{~cm}^{3}$, no. $50=725 \mathrm{~cm}^{3}$, and the smallest no. $102=9 \mathrm{~cm}^{3}$, no. $112=14 \mathrm{~cm}^{3}$ ).

\section{s-CA IX concentrated from human urine}

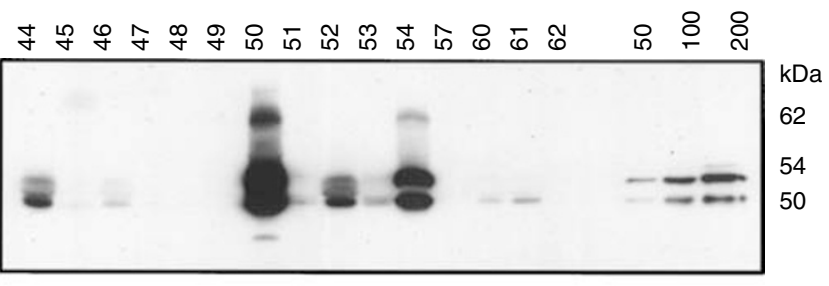

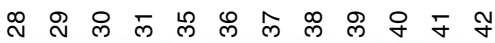

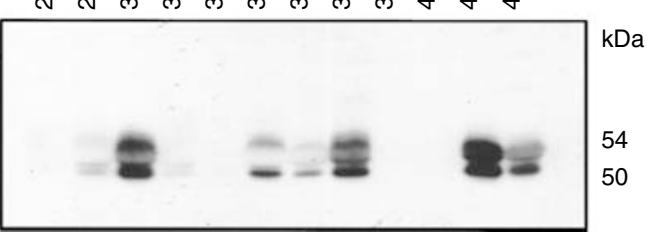

Figure 4 Carbonic anhydrase IX protein in the urine of RCC patients and control individuals. Each lane was loaded with immunoprecipitate corresponding to original $8 \mathrm{ml}$ of urine. Nontumour patients: nos. 45 and $48=$ stones in the urether; non-RCC tumour patients no. 28 and $57=$ angiolipoma and no. $39=$ papillary carcinoma. All other samples $=$ RCC (the largest were no. $36=1466 \mathrm{~cm}^{3}$, no. $50=725 \mathrm{~cm}^{3}$, the smallest no. $44=1 \mathrm{~cm}^{3}$, no. $60=12 \mathrm{~cm}^{3}$ and no. $\left.38=14 \mathrm{~cm}^{3}\right)$.

The data on CA IX concentration in biological materials tested in the course of these experiments are summarised in Table 1. The figures for cell and tumour extracts and for TC media are based on ELISA. The CA IX concentration in blood sera and in urine was determined by densitometric reading of films exposed with Western blots and calculated by a comparison with included calibration with HT29 medium, titrated in ELISA. All these figures must be taken only as very approximate, due to high biological variability (density-dependent expression of CA IX in cell cultures, volume of fluids consumed by the patients before providing the 
Table I Concentration of CA IX in biological materials

\begin{tabular}{ll}
\hline HT29 cell extract & \\
Fresh RCC extract & $4 \mathrm{mgg}^{-1}$ total protein $^{\mathrm{a}}$ \\
Normal kidney extract & $0.5-2 \mathrm{mg} \mathrm{g}^{-1}$ total protein \\
HT29 TC medium & Not detectable \\
RCC TC media & $20-50 \mathrm{ng} \mathrm{m}^{-1}$ \\
Sera of RCC patients & $20-50 \mathrm{ng} \mathrm{ml}^{-1}$ \\
Control sera & $20 \mathrm{pg}-3.6 \mathrm{ng} \mathrm{ml}^{-1}$ \\
Urine of RCC patients & $5-25 \mathrm{pg} \mathrm{ml}^{-1}$ \\
Control urine & $20 \mathrm{pg}^{-1} \mathrm{ng} \mathrm{ml}^{-1}$ \\
\hline
\end{tabular}

${ }^{\mathrm{a} A} 5$-cm Petri dish corresponds to $5 \mathrm{ml}$ of medium or to $0.5 \mathrm{mg}$ total protein extracted from the cell monolayer.

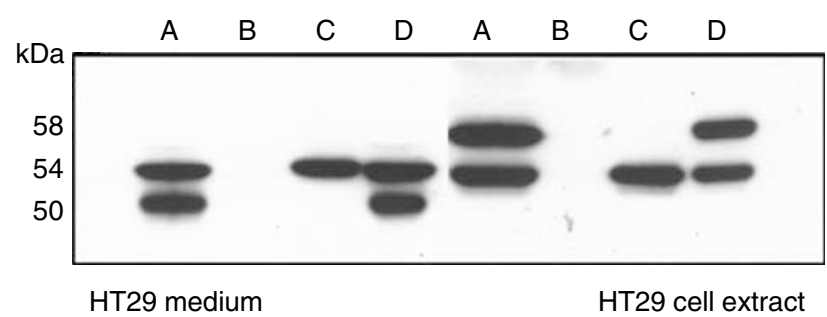

Figure 5 Recovery of CA IX bands 50 and $58 \mathrm{kDa}$ from diluted fluids after immunoprecipitation. $A=$ original TC medium or extract from HT29 cells. To the same antigens as in A was added mAb M75 (ascites fluid) and Protein A-Sepharose and after appropriate incubation, the mixtures were centrifuged and analysed; $B=$ supernatant; $C=$ pellet. With antigens from the medium, $B+C$ was mixed and analysed $=D$; with antigen from cell extract, to the pellet was added 2\% FCS (=D). All samples for the analysis were adjusted to the same concentration of CA IX protein.

urine for CA IX determination). Western blotting is only a semiquantitative method and no clearcut borderline exists between 'normal' and 'elevated' concentrations of the antigen.

\section{Recovery of CA IX 50 and $58 \mathrm{kDa}$ bands from the diluted cell extract or TC medium}

In the course of these experiments, we made an unexpected observation, which is relevant mainly from the methodical point of view, nevertheless, it cannot be omitted from this paper, since it was also encountered but not explained in other laboratories.

The concentration of CA IX in the serum and urine of RCC patients is too low to be detected without previous concentration. Therefore, we tested how efficiently CA IX can be immunoprecipitated from diluted cell extracts or TC media of HT29 cells.

The result was somewhat puzzling (Figure 5). The original cell extract or TC medium contained two bands of CA IX. However, after addition of M75 antibody followed by PA-Sepharose beads and low-speed centrifugation, no CA IX was detected in the supernatant and all CA IX antigens were present in the pellet. Surprisingly, it was seen only as a single band of $54 \mathrm{kDa}$, no matter whether it was from the cell extract or from the medium. The other band had disappeared. When the pellets were mixed with corresponding supernatants, the lost bands appeared again in their original intensity. For re-appearance of the lost band, it was sufficient to add FCS to a final concentration of $1-2 \%$. This observation suggests that FCS (or various other proteins) provides some sort of steric support for CA IX on Western blots. In this experiment, the p54 band did not disappear after adding the mAb and Protein A-Sepharose and after centrifugation, most likely because during migration in polyacrylamide gel electrophoresis and blotting it overlaps with the denatured heavy chain of M75 IgG. Since this observation, we started to add $1.5-2 \%$ of FCS to
Laemmli sample buffer to extract CA IX from the immunoprecipitates and to dilute the samples before gel electrophoresis and Western blotting.

\section{DISCUSSION}

CA IX is the only member of the family of CAs that shows a strong association with several types of human cancer. Normally, it is present only in mucosa of the alimentary tract, mainly in the stomach, but on the other hand, its expression in the tumours is ectopic as a rule. It is a relatively complex molecule, exerting at least two functions. Both of them may be of importance in normal alimentary tract as well as in tumours. One of them is enzymatic activity; CA IX belongs to carbonic anhydrases with the highest activity (Wingo et al, 2001). In addition, CA IX is a cell adhesion molecule, most likely involved in cell-to-cell communication; its binding site overlaps with the M75 epitope (Závada et al, 2000).

Recently generated $C A 9-/-$ mice cast more light on the normal function of CA IX protein: it consists in differentiation and growth regulation of gastric mucosa (Ortová-Gut et al, 2002). The role of CA IX in the chain of molecular events in the process of oncogenesis remains to be elucidated. In certain types of tumours, the expression of CA IX reflects hypoxia, resulting in a poor prognosis (for review, see Harris, 2002).

The present paper is focused on the soluble form of the CA IX protein shed by tumour cells. It answers all the questions listed in the introductory paragraph: s-CA IX is being shed from the cells into the culture medium, and compared with cell-associated protein p54/58, it is somewhat shortened (to 50 and $54 \mathrm{kDa}$ ). This size corresponds to the extracellular part of the CA IX molecule, which is composed of proteoglycan (PG)-like and CA domains that have been cleaved off the rest of the molecule - the transmembrane (TM) segment and intracellular (IC) tail of CA IX (Opavský et al, 1996). The s-CA IX contains both PG and CA domains, since it reacts with both mAb M75 specific for PG and with MAb V-10 specific for the CA domain.

Shedding of CA IX is moderately efficient; 2 days after exchange, the medium contains about $10 \%$ of the total amount of CA IX compared with the cell monolayer (Figure 2). On the other hand, the concentration of s-CA IX in the blood of RCC patients, even if they carry very large tumours, is approximately $1000 \times$ lower than in TC media (Table 1). This shows that s-CA IX is rapidly cleared from the blood. There may be several mechanisms of clearance; we have demonstrated one of them - excretion in urine without any major degradation (Figure 4). Concentration of the s-CA IX in the urine of RCC patients corresponds approximately to that in the blood. An apparently higher percentage of CA IX-positive samples of urine from RCC patients (70\%), compared with positive samples of serum (40\%) has two causes. One of them is a larger starting volume of urine for concentrating CA IX protein, while the other is a relatively higher level of CA IX in normal sera compared with control urine samples.

Possibly, some of CA IX could be degraded to smaller fragments; we are aware of the existence of CA IX-related polypeptides of 20 $30 \mathrm{kDa}$ lacking the PG domain. However, their detection and quantification will require other technical improvements. Two urine samples - nos. 50 and 54 - contain an apparently larger protein of $62 \mathrm{kDa}$ reacting with $\mathrm{mAb}$ M75. The significance of this larger protein is not clear; it was not found in the blood or in the tumour extract from the same patient.

At present, the quality of Western blots from blood and urine of RCC patients appears to be satisfactory, but admittedly, Western blotting is not really suitable as a diagnostic test for hundreds or thousands of urine samples. The present results merely show that development of appropriate methods is feasible and most likely indeed worthwhile; they may find clinical application for monitoring the patients after surgery and possibly could be helpful in deciding upon the optimum method for therapy. 


\section{ACKNOWLEDGEMENTS}

This research was supported by Bayer Corp., by Grant No. 301/99/ 0356 from the Czech Grant Agency and by VEGA Grant No. 2/ $3055 / 23$. We are grateful to Dr Eva Hamšíková, Institute of
Haematology and Blood Transfusion, Prague, for the samples of sera from blood donors, to Dr Martina Vojtěchová for preparing the figures, to Dr D Elleder for densitometry of the Western blots and to Dr Šárka Takáčová for help with preparing the manuscript.

\section{REFERENCES}

Chia SK, Wykoff CC, Watson PH, Han C, Leek RD, Pastorek J, Gatter KC, Ratcliffe P, Harris AL (2001) Prognostic significance of a novel hypoxiaregulated marker, carbonic anhydrase IX (MN/CA IX), in invasive breast carcinoma. J Clin Oncol 19: 3660 - 3668

Giatromanolaki A, Koukourakis MI, Sivridis E, Pastorek J, Wykoff CC, Gatter KC, Harris AL (2001) Expression of hypoxia-inducible carbonic anhydrase-9 relates to angiogenic pathways and independently to poor outcome in non-small cell lung cancer. Cancer Res 61: 7992-7998

Harris AL (2002) Hypoxia - a key regulatory factor in tumour growth. Nat Rev Cancer 2: $38-47$

Ivanov SV, Kuzmin I, Wei Ming-Hui, Pack S, Geil L, Johnson BE, Stanbridge EJ, Lerman MI (1998) Down-regulation of transmembrane carbonic anhydrases by wild-type von Hippel-Lindau transgenes. Proc Natl Acad Sci USA 95: 12596-12601

Koukorakis MI, Giatromanolaki A, Sivridis E, Simopoulos K, Pastorek J, Wykoff CC, Gatter KC, Harris AL (2001) Hypoxia-regulated carbonic anhydrase 9 (CA9) relates to poor vascularization and resistance of squamous cell head and neck cancer to chemotherapy. Clin Cancer Res 7: 3399-3403

Liao SY, Aurelio ON, Jan K, Závada J, Stanbridge EJ (1997) Identification of the MN/CA9 protein as a reliable diagnostic biomarker of clear cell carcinoma of the kidney. Cancer Res 57: 2827-2831

Liao SY, Brewer C, Závada J, Pastorek J, Pastoreková S, Manetta A, Berman ML, DiSaia PJ, Stanbridge EJ (1994) Identification of the MN antigen as a diagnostic biomarker of cervical intraepithelial squamous and glandular neoplasia and cervical carcinomas. Am J Pathol 145: 598-609

Opavský R, Pastoreková S, Zelník V, Gibadulinová A, Stanbridge EJ, Závada J, Kettmann R, Pastorek J (1996) Human MN/CA9 gene, a novel member of the carbonic anhydrase family: structure and exon to protein domain relationships. Genomics 33: $480-487$
Ortová-Gut $\mathrm{M}$, Parkkila S, Vernerová Z, Rohde E, Závada J, Hocker M, Pastorek J, Karttunen T, Gibadulinová A, Závadová Z, Knobeloch K-P, Wiedenmann B, Svoboda J, Horak I, Pastoreková S (2002) Gastric hyperplasia in mice with targeted disruption of the carbonic anhydrase gene Car9. Gastroenterology 123: $1889-1903$

Pastoreková S, Závadová Z, Košt'ál M, Babušiková O, Závada J (1992) A novel quasi-viral agent, MaTu, is a two-component system. Virology 187: $620-626$

Saarnio J, Parkkila S, Parkkila AK, Haukipuro K, Pastoreková S, Pastorek J, Kairaluoma MI, Karttunen TJ (1998) Immunohistochemical study of colorectal tumors for expression of a novel transmembrane carbonic anhydrase, MN/CA IX, with potential value as a marker of cell proliferation. Am J Pathol 153: 279-285

Wingo T, Tu C, Laipis PJ, Silverman DN (2001) The catalytic properties of human carbonic anhydrase IX. Biochem Biophys Res Commun 288: 666 669

Zat'ovičová M, Tarábková K, Švastová E, Gibadulinová A, Mucha V, Jakubičková L, Biesová Z, Ortova Gut M, Parkkila S, Parkkila A-K, Waheed A, Sly WS, Horak I, Pastorek J, Pastoreková S (2003) Monoclonal antibodies generated in CA IX-deficient mice recognize different domains of tumor-associated hypoxia-induced carbonic anhydrase IX. J Immunol Methods, (submitted)

Závada J, Závadová Z, Pastorek J, Biesová Z, Ježek J, Velek J (2000) Human tumour-associated cell adhesion protein MN/CA IX: Identification of M75 epitope and of the region mediating cell adhesion. Br J Cancer 82: $1808-1813$

Závada J, Závadová Z, Pastoreková S, Čiampor F, Pastorek J, Zelník V (1993) Expression of MaTu-MN protein in human tumor cultures and in clinical specimens. Int J Cancer 54: 268-274 